\title{
CROSS-SECTIONAL STUDY OF ASSOCIATION BETWEEN GLYCEMIC CONTROL AND QUALITY OF LIFE AMONG DIABETIC PATIENTS
}

\author{
ANITA NATASYA, RETNOSARI ANDRAJATI*, RANI SAURIASARI \\ Department of Clinical Pharmacy, Faculty of Pharmacy, Universitas Indonesia, Depok, 16424, Indonesia. Email: andrajati@farmasi.ui.ac.id \\ Received: 30 June 2018, Revised and Accepted: 28 September 2018 and 30 November 2018
}

\section{ABSTRACT}

Objective: The present study aimed to evaluate the association between glycemic control and quality of life (QoL) in people with type 2 diabetes mellitus (T2DM) and identify that factors that influence glycemic control and QoL.

Methods: This cross-sectional study was conducted at the general hospital in Depok City from October to December 2017. Respondents were outpatients diagnosed with T2DM, receiving routine care at the hospital. Glycemic control was assessed using glycated hemoglobin (HbA1c) levels, while QoL was measured using an Indonesian version of the validated 5-level EuroQol 5-Dimensional.

Results: Among 108 participants, HbA1c levels were influenced by age, DM disease duration, DM treatment adherence, glycemic control, diet, and physical activity suitable for patients with DM. The mean QoL value was $0.74 \pm 0.23$ and the visual analog scale (VAS) score was $65.49 \pm 15.96$. The QoL values of patients with DM were influenced by HbA1c levels, duration of DM, and physical activity, while the VAS score was significantly affected by HbA1c levels and duration of DM.

Conclusion: The present study showed that the QoL of T2DM patients was significantly influenced by glycemic control and other factors.

Keywords: Type 2 diabetes mellitus, Quality of life, Hemoglobin A1c, Glycemic control, 5-Level EuroQol 5-dimensional.

(C) 2018 The Authors. Published by Innovare Academic Sciences Pvt Ltd. This is an open access article under the CC BY license (http://creativecommons. org/licenses/by/4. 0/) DOI: http://dx.doi.org/10.22159/ijap.2018.v10s1.19

\section{INTRODUCTION}

Diabetes mellitus (DM) is a chronic disease worldwide that can lead to disabilities and even death. In 2014, the World Health Organization (WHO) stated that there were as many as 422 million people worldwide with the disease, with a prevalence of $8.5 \%$ [1]. The prevalence of DM in Indonesia is $2.1 \%$, based on the Basic Health Research and the WHO data, showing that DM is the third leading cause of death in Indonesia, with 100,400 cases $(6.5 \%)$ in 2012 [2,3]. DM is a chronic disease that requires long-term therapy and management, including selfcare behaviors. Patients with type 2 diabetes mellitus (T2DM) show symptoms of age-related depression, functional disabilities, diabetes duration, disease complications, and sociodemographic factors that affect the quality of life (QoL) $[4,5]$.

Measurements of glycemic control using glycated hemoglobin (HbA1c) values and self-monitoring of blood glucose at healthcare facilities are used to assess the effectiveness and safety of DM therapy. HbA1c monitoring should be performed routinely for all patients with DM, with a target of $<7 \%$ in non-pregnant adult patients [6]. HbA1c levels are influenced by gender, race, health insurance, DM duration, physical activity, and language understanding, whereas marital status, self-control of glucose, type of DM therapy, and antihypertensive and anticholesterol drug use do not significantly affect this index [6-8]. QoL is affected by age, gender, race, comorbidities, occupational status, and educational level [6]. Low glycemic control also affects the QoL of patients with diabetes, although some studies suggest that the QoL of patients with DM is not affected by HbA1c levels [9-13].

The 5-level EuroQol 5-Dimensional (EQ-5D-5L) is a standard QoL assessment tool that was developed by the EuroQol Group and has various language versions. Other versions of the EQ-5D include the EQ-5D-3L and EQ-5D-Y, which can be used for adolescent patients [14]. A study comparing EQ-5D-5L and EQ-5D-3L concluded that the EQ-5D-5L version had a much higher distinguishing power than the EQ-5D-3L device for patients with diabetes [5].

In 2017, the Indonesian version of the EQ-5D-5L QoL instrument was translated, validated, standardized, evaluated, and published for use as a health-related QoL tool in Indonesia [15]. The determined value set for a descriptive questionnaire can affect the value of life quality. The EQ-5D value set was compared with the EQ-5D-3L questionnaire used for cervical cancer patients in Indonesia and showed significant differences in the use of the four values set [16].

In the West Java Province of Indonesia, the prevalence of diabetes in individuals $\geq 15$ years of age is $2.0 \%$, which is increased from the prevalence of $1.3 \%$ reported in 2007. In Depok City, West Java, DM is the third most common non-communicable disease, with 21,971 cases reported in 2015 [10]. This high rate of DM seen at the general hospital in Depok City, a secondary health care facility, has drawn attention to patients with DM. To date, no studies have assessed health-related QoL and its association with glucose control in patients with DM at the general hospital in Depok City. Therefore, it is necessary to evaluate the association between glycemic control and QoL in patients with DM and to identify the influencing factors.

\section{METHODS}

The study was cross-sectional in design and was carried out at the general hospital in Depok City from October to December 2017. Respondents were outpatients diagnosed with T2DM receiving routine care at the general hospital in Depok City, with the National Health Insurance, using pharmacological therapy for the previous 3 months or longer, and had poor glycemic control based on their medical record. Those with hemoglobinopathy and mental disorders and who were pregnant and lactating were excluded from the study.

The study obtained an ethical license from the Medical Research Ethics Committee of the Faculty of Medicine, University of Indonesia. Those 
who meet the inclusion criteria and were willing to be take part in the study gave written informed consent.

The sample size was calculated by estimating the proportion of the population, and the sample obtained was at least 96 patients (Equation 1) [17]. Sample determination was carried out using consecutive method sampling. Each participant performed a glycemic control assessment using HbA1c levels, and QoL was assessed using the validated EQ-5D-5L Indonesian version (Euroqol). The study obtained permission from Euroqol to use EQ-5D-5L.

Equation 1: Sample size calculation formula

$\mathrm{n}=\frac{\left(\mathrm{Z}_{1-\infty / 2}\right)^{2}}{4 \mathrm{~d}^{2}}$

$\mathrm{n}=$ Sample size

$\mathrm{Z}_{1-} \propto / 2=$ Signification level $\alpha 0.05$

$\mathrm{d}=$ Sampling error $10 \%$

EQ-5D-5L was used as a self-administered questionnaire to give a better perspective of the respondents. EQ-5D-5L consists of QoL values using a descriptive questionnaire and visual analog scale (VAS) score to quantitatively assess the QoL on the day of measurement. QoL values were assessed using the five dimensions of mobility, self-care, usual activities, pain/discomfort, and anxiety/depression (sadness), with five levels of assessment ranging from 1 (no difficulty) to 5 (inability) for each dimension. The VAS score ranged from 0 (worst health imaginable) to 100 (best imaginable health) [10]. Descriptive data were translated to quantitative data using the Indonesian value set scale of 0 (death) to 1 (full health) [15].

Data were analyzed using Statistical Package for the Social Sciences (SPSS) version 21, and advanced calculations used univariate, bivariate, and multivariate analyses. Univariate analysis was used to measure mean, standard deviation, 95\% confidence interval, and qualitative and quantitative variables. Bivariate analysis was used to assess the correlation between variables with non-parametric tests (MannWhitney U-test or Kruskal-Wallis test) for continuous variables and Spearman's rho test for categorical variables after the normality of the data was checked. Multivariate analysis was used to model the association between the QoL (QoL values and VAS score) and sociodemographic and clinical factors. A $5 \%(\mathrm{p}<0.05)$ level of significance was established to eliminate the null hypothesis. Independent variables, such as the use of an adherence assessment using a pill count test, as well as diet and physical activity, were assessed by a nutritionist at the hospital.

\section{RESULTS}

At the end of 2017, there were 746 outpatients with T2DM at the general hospital in Depok City; however, only 111 of these fulfilled the inclusion criteria. One patient had a mental disorder and two were unwilling to participate, resulting in a total sample of 108 patients.

The demographics and clinical characteristics of the patients with T2DM were performed by descriptive analysis (Table 1). Most (63 people, $58.3 \%)$ of the respondents were not the elderly, $74(68.5 \%)$ were women, 57 (52.8\%) had a low level of education, and $80(74.1 \%)$ were unemployed. The clinical characteristics of patients with T2DM included 49 patients $(45.4 \%)$ with a duration of disease of $1-5$ years, 43 patients (39.8\%) without comorbidities, 51 patients $(47.2 \%)$ with a history of DM, 60 patients $(55.6 \%)$ with non-adherence to DM treatment, 83 patients $(76.9 \%)$ without experience of adverse effects of DM, 57 patients (52.8\%) not adhering to the recommended diet regimen for DM patients, 49 patients (45.4\%) performing physical activity as recommended for DM patients, and 67 patients $(62.0 \%)$ did not meet the glycemic control target. HbA1c levels were affected by age $(p=0.004), H b A 1 c$ levels were affected by age $(p=0.005)$, adherence $(0.016)$, glycemic control $(p=0.000)$, diet $(p=0.000)$ and physical activity $(\mathrm{p}=0.000)$.
T2DM therapy used by the patients at the general hospital in Depok City included oral and insulin therapy, as well as single use and combination therapy (Table 2). The most frequent single drug used was metformin (5.6\%), whereas the most common combination therapies were a two-drug combination of metformin and sulfonylurea (32.4\%) and a three-drug combination of metformin, sulfonylurea, and $\alpha$-glucosidase inhibitors (29.6\%). Insulin therapy was generally combined with oral therapy $(7.4 \%)$. T2DM therapy for glycemic control and the best VAS values were achieved using a combination of metformin and sulfonylurea (HbA1c 7.16\% and VAS 70.64), while the highest QoL value (0.83) was achieved using a combination of metformin and $\alpha$-glucosidase inhibitors.

The QoL of patients with T2DM at the general hospital in Depok City was assessed using the validated EQ-5D-5L in Indonesian language. The EQ5D-5L consists of QoL values and VAS scores. QoL was assessed using Five dimensions: mobility, self care, usual activity, pain/discomfort, and anxiety/depression (sadness) (Table 3). The mean value for the QoL was $0.74 \pm 0.23$, while the mean VAS score was $65.49 \pm 15.96$.

Table 4 shows descriptive data for QoL based on patient characteristics of T2DM. The QoL and VAS values of T2DM patients were higher in non-geriatric patients, those who were active at work had a duration of DM of $<1$ year, adhered to DM therapy, and did not follow nonpharmacological treatment recommendations.

The QoL of T2DM patients was different for all dimensions. Anxiety/ depression was affected by duration of T2DM, adverse effects, and physical activity of the patient, while mobility and discomfort were affected by employment status. Self-care and usual activities were not influenced by clinical factors (Table 5). The association between the value of QoL and VAS score with sociodemographic and clinical factors was assessed by linear regression analysis (Table 6). The QoL value was influenced by HbA1c value, DM duration, and physical activity $(\mathrm{p}=0.008$, $\mathrm{R}^{2}=10.6 \%$ ). The VAS values were influenced by HbA1c and DM duration $\left(\mathrm{p}=0.003, \mathrm{R}^{2}=10.3 \%\right)$.

\section{DISCUSSION}

In the present study, 108 outpatients with T2DM had an average HbA1c of $7.99 \pm 1.89$. Patients were included in this study based on factors that influence glycemic control, such as DM-targeted therapy. Previous studies showed that HbA1c levels are influenced by gender, ethnicity, health insurance, DM duration, physical activity, and understanding of language [6-8]. In this study, health insurance and understanding of language were not included as independent factors because most patients in Depok City already have national health insurance and understand Indonesian languages.

The demographic and clinical characteristics of patients with T2DM were assessed through descriptive analyses and using SPSS version 21 . The demographic characteristics of the participants, including nonelderly age, female, low education level, and inactive work life, were similar to the findings of Rwegerara et al., showing that the majority of DM patients were women $(69.5 \%)$, had a first-degree education $(47.6 \%)$, were $<54$ years of age $(41.8 \%)$, and had a disease duration of $<5$ years (49.2\%). Vidal-Peracho et al. also observed that the majority of patients with T2DM were female (74\%) and inactive (89.6\%) [18-19].

The majority of participants did not have a coexisting disease (39.8\%), and the study site was a secondary level health-care facility. Patients requiring drugs outside the medicine list of primary health care facilities were recommended to secondary health facilities. The clinical characteristics of the participants who were on non-pharmacological therapy, namely diet and exercise, were similar to those observed by Vidal-Peracho et al. The majority of patients performed the physical activity as directed but did not follow an appropriate diet for patients with DM [19].

Correlations were analyzed between $\mathrm{HbA1c}$ and age, gender, education level, occupational status, DM duration, comorbidities, family history of DM, 
Table 1: Characteristic distribution of T2DM patients

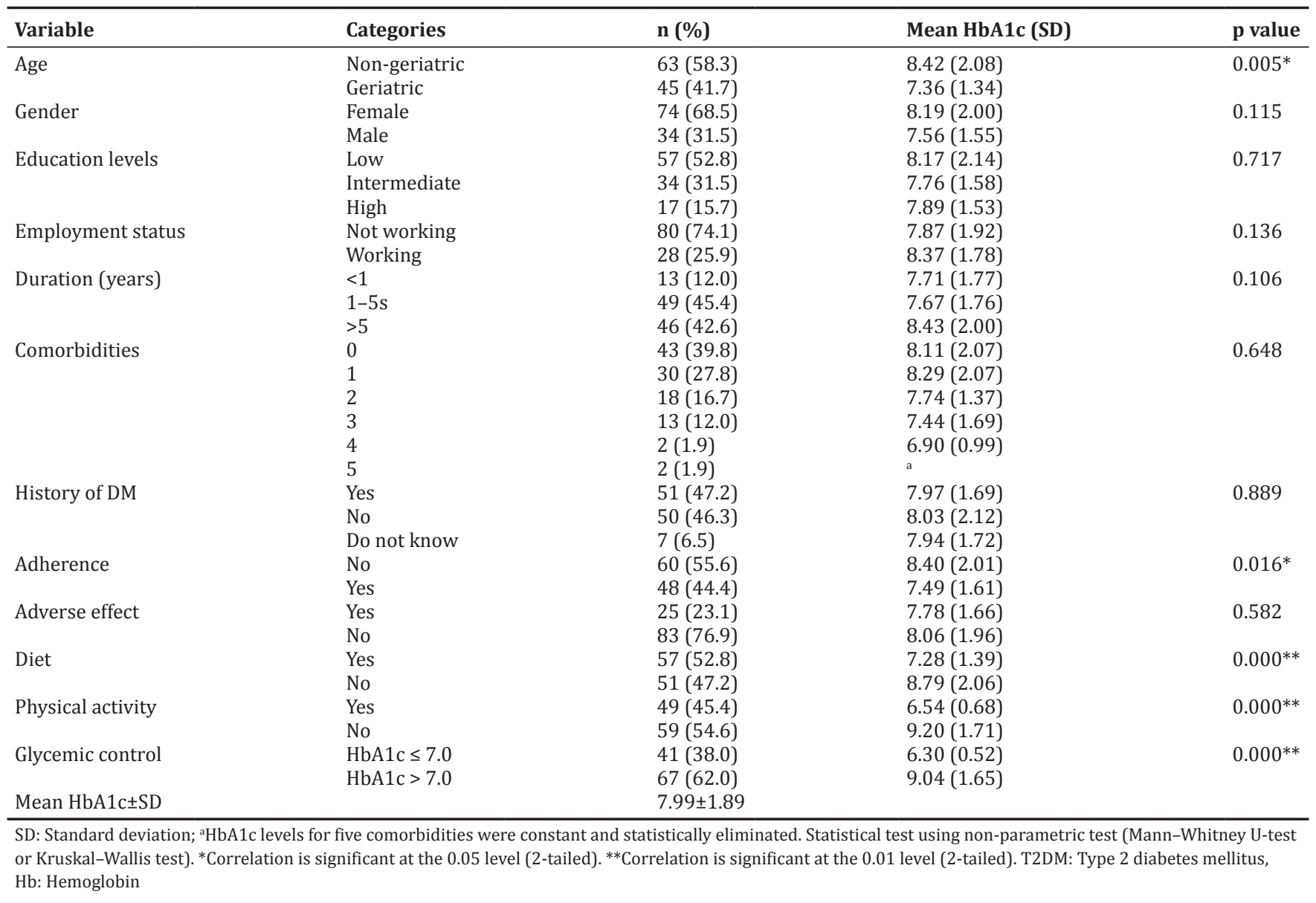

Table 2: Distribution of drug use for DM treatment in patients with T2DM (n=108)

\begin{tabular}{|c|c|c|c|c|}
\hline Therapy & n (\%) & Mean HbA1c (SD) & QoL value (SD) & VAS (SD) \\
\hline \multicolumn{5}{|l|}{ Oral monotherapy } \\
\hline Biguanide & $6(5.6)$ & $7.72(1.59)$ & $0.79(0.17)$ & $69.17(8.01)$ \\
\hline Sulfonylurea & $3(2.8)$ & $7.97(2.54)$ & $0.59(0.63)$ & $53.33(40.41)$ \\
\hline$\alpha$-Glucosidase Inhibitor & $1(0.9)$ & 13.40 & 0.92 & 55.00 \\
\hline \multicolumn{5}{|l|}{ Oral combination therapy } \\
\hline Biguanide+Sulfonylurea & $35(32,4)$ & $7.16(1.10)$ & $0.76(0.21)$ & $70.64(14.99)$ \\
\hline Biguanide $+\alpha-$-Glucosidase inhibitor & $2(1,9)$ & $8.83(0.87)$ & $0.83(0.15)$ & $64.33(22.28)$ \\
\hline Biguanide + Sulfonylurea $+\alpha$-Glucosidase inhibitor & $32(29.6)$ & $7.98(2.11)$ & $0.73(0.22)$ & $65.69(15.26)$ \\
\hline \multicolumn{5}{|l|}{ Insulin therapy } \\
\hline Insulin & $7(6.5)$ & $9.76(0.60)$ & $0.68(0.33)$ & $59.29(15.39)$ \\
\hline Insulin+Biguanide & $8(7.4)$ & $8.59(1.00)$ & $0.70(0.19)$ & $60.00(11.95)$ \\
\hline Insulin+Sulfonylurea & $1(0.9)$ & 9.50 & 1.00 & 70.00 \\
\hline Insulin $+\alpha$-Glucosidase inhibitor & $2(1.9)$ & $8.20(1.13)$ & $0.77(0.04)$ & $60.00(14.14)$ \\
\hline Insulin+Biguanide+Sulfonylurea & $1(0.9)$ & 12.4 & 0.82 & 30.00 \\
\hline Insulin+Biguanide + Sulfonylurea $+\alpha-$-Glucosidase inhibitor & $1(0.9)$ & 11.50 & 0.22 & 45.00 \\
\hline
\end{tabular}

SD: Standard deviation, QoL: Quality of life, T2DM: Type 2 diabetes mellitus, Hb: Hemoglobin, VAS: Visual analog scale

DM treatment adherence, side effects, glycemic control, diet, and physical activity. Among the participants, HbA1c levels were influenced by age, DM disease duration, DM treatment adherence, glycemic control, diet, and physical activity suitable for patients with DM. Ostgren et al. demonstrated a significant correlation between DM duration and HbA1c levels $(\mathrm{p}<0.001)$. The association between DM duration and HbA1c is related to the patient's ability to perform self-care, especially diet regulation, physical activity, drug use, and control of blood glucose levels [20].

Single-drug therapy is the first-line treatment for T2DM, and the most commonly used drug is metformin as it has a long-term safety profile and is well tolerated by most patients [13]. Metformin can help patients' lose weight, and gastrointestinal tract side effects can be avoided by consumption after meals.

QoL was measured using a value set of EQ-5D-5L in Indonesian language, which was tested in 1054 respondents in Indonesia in a study by Purba et al. The result of this study showed that the value set could be used as a health and life quality measurement tool in Indonesia [15]. The average of QoL value was $0.74 \pm 0.23$, ranging from 0 (worst QoL) to 1 (perfect QoL). In addition, the patients' mean VAS score was $65.49 \pm 15.96$, ranging from 0 (best imaginable health) to 100 (worst health imaginable). The 
Table 3: Quality of life of T2DM patients at Depok City Hospital (n=108)

\begin{tabular}{|c|c|c|c|c|c|c|}
\hline \multirow[t]{2}{*}{ Quality of life dimensions } & \multicolumn{5}{|l|}{ n (\%) } & \multirow[t]{2}{*}{ Mean \pm SD } \\
\hline & No Problems (1) & Slight problems (2) & Moderate problems (3) & Severe problems (4) & Unable (5) & \\
\hline Mobility & $60(55.6)$ & $29(26.8)$ & $14(13.0)$ & $5(4.6)$ & $0(0)$ & $1.67 \pm 0.88$ \\
\hline Usual activities & $78(72.2)$ & $19(17.6)$ & $11(10.2)$ & $0(0)$ & $0(0)$ & $1.38 \pm 0.66$ \\
\hline Pain/discomfort & $38(35.2)$ & $45(41.7)$ & $15(13.9)$ & $10(9.2)$ & $0(0)$ & $1.97 \pm 0.93$ \\
\hline Anxiety/depression & $45(41.7)$ & $40(37.0)$ & $14(13.0)$ & $8(7.4)$ & $1(0.9)$ & $1.89 \pm 0.23$ \\
\hline Mean quality of life value & & & & & & $0.74 \pm 0.23$ \\
\hline Mean VAS score & & & & & & $65.49 \pm 15.96$ \\
\hline
\end{tabular}

SD: Standard deviation. T2DM: Type 2 diabetes mellitus, VAS: Visual analog scale

Table 4: Descriptive analysis of characteristics and quality of life T2DM patients

\begin{tabular}{|c|c|c|c|}
\hline Variable & Categories & QoL value \pm SD & $\mathrm{VAS} \pm \mathrm{SD}$ \\
\hline \multirow[t]{2}{*}{ Age } & Non-geriatric & $0.75 \pm 0.22$ & $66.54 \pm 14.99$ \\
\hline & Geriatric & $0.72 \pm 0.25$ & $63.91 \pm 17.39$ \\
\hline \multirow[t]{2}{*}{ Gender } & Female & $0.78 \pm 0.19$ & $64.50 \pm 17.22$ \\
\hline & Male & $0.72 \pm 0.24$ & $65.95 \pm 15.45$ \\
\hline \multirow[t]{3}{*}{ Education levels } & Low & $0.72 \pm 0.23$ & $63.86 \pm 15.95$ \\
\hline & Intermediate & $0.72 \pm 0.25$ & $67.96 \pm 15.54$ \\
\hline & High & $0.85 \pm 0.18$ & $67.18 \pm 17.19$ \\
\hline Employment status & Working & $0.72 \pm 0.24$ & $65.01-15.93$ \\
\hline \multirow[t]{3}{*}{ Duration (years) } & $<1$ & $0.79 \pm 0.13$ & $78.69 \pm 8.20$ \\
\hline & $1-5$ & $0.72 \pm 0.24$ & $64.94 \pm 15.42$ \\
\hline & $>5$ & $0.75 \pm 0.25$ & $62.35 \pm 16.55$ \\
\hline \multirow[t]{4}{*}{ Comorbidities } & 0 & $0.77 \pm 0.17$ & $65.72 \pm 13.35$ \\
\hline & 1 & $0.74 \pm 0.25$ & $66.00 \pm 16.83$ \\
\hline & 2 & $0.68 \pm 0.32$ & $66.50 \pm 19.80$ \\
\hline & 3 & $0.74 \pm 0.24$ & $60.77 \pm 18.00$ \\
\hline \multirow[t]{3}{*}{ History of DM } & Yes & $0.72 \pm 0.21$ & $66.03 \pm 15.47$ \\
\hline & No & $0.78 \pm 0.22$ & $65.28 \pm 16.96$ \\
\hline & Do not know & $0.54 \pm 0.3$ & $64.29 \pm 13.97$ \\
\hline \multirow[t]{2}{*}{ Adherence } & No & $0.77 \pm 0.19$ & $67.14 \pm 15.05$ \\
\hline & Yes & $0.71 \pm 0.25$ & $64.17 \pm 16.66$ \\
\hline \multirow[t]{2}{*}{ Adverse effect } & No & $0.68 \pm 0.26$ & $66.12 \pm 18.94$ \\
\hline & Yes & $0.76 \pm 0.22$ & $65.30 \pm 15.08$ \\
\hline \multirow[t]{2}{*}{ Diet } & No & $0.70 \pm 0.26$ & $63.78 \pm 16.77$ \\
\hline & Yes & $0.77 \pm 0.20$ & $67.02 \pm 15.19$ \\
\hline \multirow[t]{2}{*}{ Physical activity } & No & $0.73 \pm 0.21$ & $64.03 \pm 13.11$ \\
\hline & Yes & $0.76 \pm 0.26$ & $67.24 \pm 18.84$ \\
\hline
\end{tabular}

QoL: Quality of life, SD: Standard deviation, CI: Confidence interval, T2DM: Type 2 diabetes mellitus, VAS: Visual analog scale

Table 5: Correlation characteristics and quality of life of T2DM patients

\begin{tabular}{|c|c|c|c|c|c|c|c|}
\hline \multirow[t]{3}{*}{ Variable } & \multicolumn{7}{|l|}{ p value } \\
\hline & \multicolumn{5}{|c|}{ Quality of life dimensions } & \multirow[t]{2}{*}{ QoL value } & \multirow[t]{2}{*}{ VAS } \\
\hline & Mobility & Self-care & Usual activities & Pain/discomfort & Anxiety/depression & & \\
\hline Age & 0.079 & 0.800 & 0.364 & 0.336 & 0.501 & 0.591 & 0.477 \\
\hline Gender & $0.043^{*}$ & 0.309 & 0.716 & 0.430 & 0.795 & 0.259 & 0.588 \\
\hline Education levels & 0.064 & 0.318 & 0.076 & 0.131 & 0.364 & 0.061 & 0.434 \\
\hline Employment status & $0.033^{*}$ & 0.107 & 0.189 & $0.037^{*}$ & 0.364 & 0.068 & 0.713 \\
\hline History of DM & 0.992 & 0.463 & 0.790 & 0.918 & 0.234 & $0.046^{*}$ & 0.925 \\
\hline Duration of DM & 0.301 & 0.286 & 0.996 & 0.931 & $0.008^{* *}$ & 0.739 & $0.002^{* *}$ \\
\hline Comorbidities & 0.096 & 0.528 & 0.420 & 0.528 & 0.127 & 0.587 & 0.752 \\
\hline Adverse effect & 0.672 & 0.573 & 0.501 & 0.141 & $0.008^{* *}$ & 0.109 & 0.556 \\
\hline Adherence & 0.285 & 0.318 & 0.159 & 0.234 & 0.448 & 0.325 & 0.458 \\
\hline Diet & 0.156 & 0.917 & 0.882 & 0.347 & 0.144 & 0.195 & 0.412 \\
\hline Physical activity & 0.873 & 0.297 & 0.910 & 0.091 & $0.046^{*}$ & 0.215 & 0.161 \\
\hline
\end{tabular}

Statistical test by non-parametric test (Mann-Whitney U-test or Kruskal-Wallis test) for continuous variables and Spearman's rho test for categorical variables

${ }^{*}$ Correlation is significant at the 0.05 level (2-tailed). ${ }^{*}$ Correlation is significant at the 0.01 level (2-tailed). QoL: Quality of life, T2DM: Type 2 diabetes mellitus,

VAS: Visual analog scale 
Table 6: Linear regression model of the quality of life

\begin{tabular}{llll}
\hline Model & $\mathbf{R}^{\mathbf{2}}$ & Standardized coefficient $\boldsymbol{\beta}$ & $\mathbf{p}$ value \\
\hline Quality of life value & 10.6 & & 0.008 \\
HbA1c levels & & -0.226 & 0.090 \\
Duration of DM & & -0.241 & 0.012 \\
Physical activity & & 0.079 & 0.549 \\
VAS value & 10.3 & & 0.003 \\
HbA1c levels & & -0.170 & 0.072 \\
Duration of DM & & -0.244 & 0.011 \\
\hline
\end{tabular}

DM: Diabetes mellitus, VAS: Visual analog scale, HB: Hemoglobin

QoL of T2DM patients was 0.724 (range, 0-1) and 0.720 (range, 0-1) using EQ-5D-3L and EQ-5D-5L instruments, respectively. Compared with EQ-5D-3L, the EQ-5D-5L version had higher $\mathrm{H}^{\prime}$ in all dimensions, and it was concluded that the EQ-5D-5L version was more discriminative than the EQ-5D-3L version [5]. The QoL of patients assessed using the COOPWONCA instrument was 18.7 (range, 7-35) [19].

The QoL of patients with DM was influenced by HbA1c levels, duration of DM, and physical activity, while the VAS was significantly affected by HbA1c levels and duration of DM. Similar results were observed by Kuznetsov, L., Griffin, S., Davies, H., Lauritzen, T., Khunti, K., Rutten, G., Simmons, R who showed that QoL and duration of DM were associated with HbA1c levels [21]. Previous studies on QoL showed that patients with T2DM can be influenced by self-care behaviors, including nutrition and blood glucose control. Among the self-care behaviors, nutrition may be the most important predictive factor [22]. In the present study, diet, as suggested by a nutritionist, did not influence either the value of QoL or VAS score.

QoL values obtained using the EQ-5D-5L instrument were derived from a descriptive questionnaire and were not always consistent with VAS scores. A previous study using EQ-5D and EQ-VAS questionnaires on the quality-adjusted life year of diabetic retinopathy patients had more significant VAS score results compared with assessment using the EQ5D descriptive questionnaire [23]. In the present study, differences were seen between the QoL value and VAS score and the factors associated with QoL. This shows that the QoL value should not always be based on a descriptive questionnaire, as the VAS score can generate results in line with the QoL value because the methods used are different.

The present study had certain limitations. The study was cross-sectional and further constrained by the elimination criteria and targeted only those with T2DM. From a population of 746 at the hospital, only 108 patients were included.

\section{CONCLUSION}

The QoL values of patients with DM were influenced by HbA1c levels, duration of DM, and physical activity, while the VAS score was significantly affected by HbA1c levels and duration of DM. Anxiety/ depression was affected by the duration of T2DM, adverse effects, and physical activity of the patient, while mobility and discomfort were affected by employment status. Self-care and usual activities were not influenced by clinical factors, while HbA1c levels were influenced by age, DM disease duration, DM treatment adherence, glycemic control, diet, and physical activity suitable for patients with DM.

\section{CONFLICTS OF INTEREST}

This study was performed independent of any relationships, and the authors have indicated that they have no conflicts of interest regarding the content of this article.

\section{REFERENCES}

1. World Health Organization. Global Report on Diabetes. Geneva: World Health Organization; 2015. Available from: http:/www.apps.who.int/ iris/bitstream/10665/204871/1/9789241565257 eng.pdf. [Last cited on
2017 Apr 28].

2. Larasati TA. Quality of life patient with diabetes melitus Type 2 in Abdul Moeloek hospital province lampung. J Kedokteran Kesehatan Univ Lampung 2012;2:17-20.

3. World Health Organization. Global Health Observatory (GHO) Data: Mortality and Global Health Estimates. Geneva: World Health Organization; 2015. Available from: http://who.int/gho/mortality_ burden_disease/en. [Last cited on 2017 Apr 28]

4. Ostgren C, Lindbland U, Ranstam J, Melander A, Rastam L. Glycemic control, disease duration and $\beta$-cell function in patients with type 2 diabetes in a Swedish community. Diabetes Med 2002;19:125-9.

5. Wang P, Luo N, Tai ES, Thumboo J. The EQ-5D-5L is more discriminative than the EQ-5D-3L in patients with diabetes in Singapore. Value Health Reg Issues 2016;9:57-62.

6. American Diabetes Association. Standards of medical care in diabetes-2017. Diabetes Care 2017;40 Suppl 1:S1-35.

7. Shah BM, Mezzio DJ, Ho J, Ip EJ. Association of ABC (HbA1c, blood pressure, LDL-cholesterol) goal attainment with depression and healthrelated quality of life among adults with Type 2 diabetes. J Diabetes Complications 2015;29:794-800.

8. AminiLari Z, Fararouei M, Amanat S, Sinaei E, Dianatinasab S, AminiLari $\mathrm{M}$, et al. The effect of 12 weeks aerobic, resistance, and combined exercises on omentin-1 levels and insulin resistance among Type 2 diabetic middle-aged women. Diabetes Metab J 2017;41:205-12.

9. Aro AK, Karjalainen M, Tiihonen M, Kautiainen H, Saltevo J, Haanpää M, et al. Glycemic control and health-related quality of life among older home-dwelling primary care patients with diabetes. Prim Care Diabetes 2017;11:577-82.

10. EuroQol Research Foundation. EQ-5D Instruments: About EQ-5D. Rotterdam: EuroQol Research Foundation; 2017. Available from: https://www.euroqol.org/deq-5d-instruments. [Last cited $2017 \mathrm{Apr} 28$ ].

11. Bourdel-Marchasson I, Druet C, Helmer C, Eschwege E, Lecomte P, Le-Goff M, et al. Correlates of health-related quality of life in French people with Type 2 diabetes. Diabetes Res Clin Pract 2013;101:226-35.

12. Sakamaki H, Ikeda S, Ikegami N, Uchigata Y, Iwamoto Y, Origasa H, et al. Measurement of HRQL using EQ-5D in patients with Type 2 diabetes mellitus in Japan. Value Health 2006;9:47-53.

13. Triplitt CL, Reasner CA. Diabetes mellitus. In: Dipiro JT, Talbert RL, Yee GC, Matzke GR, Wells BG, Posey LM, editors. Pharmacotherapy. A Pathophysiologic Approach. 10 $0^{\text {th }}$ ed. New York: The McGraw-Hill Medical; 2017. p. 3212-92.

14. Kuznetsov L, Griffin SJ, Davies MJ, Lauritzen T, Khunti K, Rutten GE, et al. Diabetes-specific quality of life but not health status is independently associated with glycaemic control among patients with type 2 diabetes: A cross-sectional analysis of the ADDITION-Europe trial cohort. Diabetes Res Clin Pract 2014;104:281-7.

15. Purba FD, Hunfeld JA, Iskandarsyah A, Fitriana TS, Sadarjoen SS, Ramos-Goñi JM, et al. The Indonesian EQ-5D-5L value set. Pharmacoeconomics 2017;35:1153-65.

16. Endarti D, Riewpaiboon A, Thavorncharoensap M, Praditsitthikorn N, Hutubessy R, Kristina SA, et al. A comparison of EQ-5D-3L index scores using Malaysian, Singaporean, Thai, and UK value sets in Indonesian cervical cancer patients. Value Health Reg Issues 2018;15:50-5.

17. Lemeshow S, Hosmer DW, Klar J, Lwanga SK. Adequacy of Sample Size in Health Studies. England: World Health Organization; 1990.

18. Rwegerera G, Moshomo T, Gaenamong M, et al. Health-related quality of life and associated factors among patients with diabetes mellitus in Botswana. AJM 2017;54:111-8.

19. Vidal-Peracho C, Lucha-López MO, Lucha-López AC, Tricás-Moreno JM, Estébanez-De Miguel E, Bernués-Vázquez L, et al. A descriptive study of health status and health related quality of life in selected outpatients with type 2 diabetes, pathological body mass index and cardiovascular risk in Spain. Diabetol Metab Syndr 2014;6:135.

20. Parsa P,Ahmadinia-Tabesh R, Mohammadi Y, Khorami N. Investigating the relationship between quality of life with lipid and glucose levels in Iranian diabetic patients. Diabetes Metab Syndr 2017;11 Suppl 2:S879-S883.

21. Ma Q, Liu H, Xiang G, Shan W, Xing W. Association between glycated hemoglobin A1c levels with age and gender in Chinese adult with no prior diagnosis of diabetes mellitus. Biomed Rep 2016;4:737-40.

22. Babazadeh T, Dianatinasab M, Daemi A, Nikbakht HA, Moradi F, Ghaffari-Fam S, et al. Association of self-care behaviors and quality of life among patients with Type 2 diabetes mellitus: Chaldoran county, Iran. Diabetes Metab J 2017;41:449-56.

23. Heintz E, Wiréhn AB, Peebo BB, Rosenqvist U, Levin LA. QALY weights for diabetic retinopathy - a comparison of health state valuations with HUI-3, EQ-5D, EQ-VAS, and TTO. Value Health 2012;15:475-84. 